Article

\title{
Faculty Perception of Inclusion in the University: Concept, Policies and Educational Practices
}

\author{
Ana Maria Moral Mora ${ }^{1, *}$, Inmaculada Chiva ${ }^{1}$ and Carmen Lloret-Catala ${ }^{2}$ \\ ${ }^{1}$ Department of Research Methods and Educational Diagnosis, University of Valencia, Spain; \\ E-Mails: ana.moral@uv.es (A.M.M.M.), inmaculada.chiva@uv.es (I.C.) \\ 2 Department of Comparative Education and Education History, University of Valencia, Spain; \\ E-Mail: m.carmen.lloret@uv.es \\ * Corresponding author
}

Submitted: 30 January 2021 | Accepted: 18 May 2021 | Published: 21 July 2021

\begin{abstract}
European universities must face the challenge of diversity and design inclusive practices to address it as part of their social responsibility. However, not all universities are doing the same in terms of diversity practices, so it is important to gather the perceptions of the protagonists. To this end, we have analysed university faculty's perceptions using a mixed model with a concurrent methodological strategy, including an ad hoc questionnaire validated with 880 educators, as well as 17 semi-structured interviews. The triangulation of these two instruments allowed us to analyse three key dimensions associated with the idea of attention to diversity in the university: diversity concept or culture, policies and programmes of the institution, and inclusive educational practices. The conclusion is that faculty members are positively predisposed to get involved in the process of attention to diversity in all three dimensions, especially in the design of inclusive teaching practices such as the UDL (universal design for learning), although they do point out that it is important to systematise diversity policies in research, innovation, and teaching to keep promoting the social commitment and responsibility of higher education institutions.
\end{abstract}

\section{Keywords}

attention to diversity; equity; faculty; higher education; mixed methods; universal design for learning; university policies; university students

\section{Issue}

This article is part of the issue "Inclusive Universities in a Globalized World" edited by Liudvika Leišyte (TU Dortmund, Germany), Rosemary Deem (Royal Holloway, UK) and Charikleia Tzanakou (Oxford Brookes University, UK).

(C) 2021 by the authors; licensee Cogitatio (Lisbon, Portugal). This article is licensed under a Creative Commons Attribution 4.0 International License (CC BY).

\section{Introduction}

Achieving educational inclusion to alleviate social inequalities is one of the main aspirations of the different European higher education systems, and has become a societal priority (European Commission, 2010; Eurydice, 2011).

Despite the controversial discourse surrounding the implementation of inclusive educational modelsfocusing on the rationale for and realisation of inclusion-inclusive education is undoubtedly a funda- mental human right based on an egalitarian society, and it requires the design of policies, strategies, processes, and actions to guarantee the success of all students. This is the only vision of education that promotes social justice, against traditional segregated education (Dyson, 1999; Moriña, 2017).

We might say that a democratic society is based on the idea that education must be guaranteed for all students, especially for those who are disadvantaged. To achieve this objective, universities must undergo a process of educational inclusion (Ainscow et al., 2013; 
Díaz-Jiménez, 2019). Recent international agreements of great historical relevance such as the 2030 Agenda (United Nations, 2015) - through its fourth Sustainable Development Goal-require ensuring "inclusive and equitable quality education and promote lifelong learning opportunities for all" (Kestin et al., 2017). University education must support the active participation of students and training opportunities on an equal footing for everyone (Díaz-Jiménez, 2019), guaranteeing the right to education regardless of the personal and social circumstances of the students, as well as their economic situation, gender, ethnicity, age, or disability (European Agency for Special Needs and Inclusive Education, 2012). Higher education must be a referent for the development of an inclusive education model that integrates equality, equity, accessibility, and excellence (Benet, 2020). All of these aspects are reflected in a learning model based on the universal design for learning (UDL) methodology, which makes it possible to adapt and transform educational practices to make them accessible to all university students. UDL contributes to the significant implementation of inclusion to improve learning for all university students, which in turn contributes to the improvement of faculty practices, enhanced by university policies that follow these inclusive principles.

Therefore, faculty members are fundamental actors in the promotion of educational inclusion in higher education institutions (Benet et al., 2019; Díez-Villoria \& Sánchez Fuentes, 2015; Forlin et al., 2011). As such, the objective of this study is to address the current state of inclusion in higher education from the perspective of the teaching staff, regarding three main aspects: their diversity concept or culture, the related policies and programmes of the institution, and the transformative practices carried out by the faculty. We will take a look at how they define attention to diversity, what their perception is of educational policies related to inclusion, and what they consider to be the best methods and practices aimed at true educational inclusion in the university environment.

\section{Theoretical Basis}

According to Booth and Ainscow (1998), walking towards more inclusive communities/universities-and, consequently, more inclusive societies-involves addressing three closely-related dimensions: educational culture, policies, and practices. More specifically, with the development of a more inclusive culture, policy and practice changes might follow. Successful changes would become established and be passed on to new members of the educational community (Booth \& Ainscow, 2015).

\subsection{Concept of Attention to Diversity in Higher Education}

The concept of attention to diversity in the university context has been reviewed from the perspective of inclu- sive education for all (Dyson, 1999), with the understanding that this idea of diversity in higher education contemplates different ideological perspectives depending on the meaning ascribed to the term and the associated area of research. Traditionally, in the American context, two different expressions are used, namely students of different race or ethnicity on the one hand, and socially disadvantaged students on the other, these last ones with a low socioeconomic level: "Given this context, it is important to examine the current and historical discourses of both 'diversity' (race and ethnicity) and 'disadvantage' (socio-economic status) employed by many colleges and universities" (Grant \& Allweiss, 2014, p. 34).

Conversely, in European universities, the idea of diversity tends to be related to cognitive and functional differences (Díaz-Jiménez, 2019), in addition to gender. Above all, the concept of diversity in university is connected to disability and learning difficulties (Benet et al., 2019; Biewer et al., 2015; Grant \& Allweiss, 2014; Hardy \& Woodcock, 2015). There are more and more voices that include in the definition of diversity the need to consider the student body from a social, culturalintercultural, and gender perspective, as a more global entity (Klein, 2016).

Diversity is understood as difference, and 'attention to diversity' as the educational intervention towards those people with regards to their characteristics. Langa-Rosado and Lubián-Graña (2021) have published a study questioning whether attention to diversity is perceived as the attention to that which is diversethe traditional understanding of attention to deficitsor in a broader sense-including different capacities, different genders, and different social and cultural backgrounds understood as richness, rather than a problem (Moriña, 2017).

For this reason, the study of the faculty's perception of what 'attention to diversity and inclusion' means conditions the type of teaching methodology and practices developed in the classroom, the way they understand the particularities of university students, and how they understand and apply inclusive policies (Díez-Villoria \& Sánchez Fuentes, 2015; Forlin et al., 2011).

\subsection{Inclusive Policies at the University}

The number of diverse students in higher education has progressively increased (Lombardi et al., 2015), and universities are more and more aware every day of the need to make organisational changes focusing on the fight against systemic inequalities and marginalisation (Goldberg et al., 2019). Universities have the responsibility to respond to all sorts of diversities and ensure that the needs of the students are met, with inclusion functioning as a seal of quality. The development of educational policies to guarantee widespread access to education and contribute to ensuring the success of all students, and a satisfactory educational process, are 
essential to combat the pervasive nature of exclusion. In addition, inclusive education and training are essential to guarantee social mobility and inclusion, and offer knowledge and skills to access the labour market, as well as to promote critical thinking competences and a deeper understanding of common values (European Commission, 2018). An inclusive university is based on diversity as a value, on empowerment, participation, and democracy; it is a place where the fight against exclusion, discrimination, and inequality must be apparent and everyone is accepted and supported, where differences between individuals enrich interpersonal relationships and the overall learning process (Moliner \& Moliner, 2010). This is a great challenge, because the characteristics of higher education systems turn change management into a complex issue (O'Donnell, 2016).

Scientific literature makes it clear that, although some administrations are starting to propose inclusive university policies, the legal framework is still insufficient and does not guarantee (at least not on its own) quality, non-discriminatory education that can contribute to a more inclusive education (Langa-Rosado \& Lubián-Graña, 2021; Moriña et al., 2017). The question is not whether inclusion should exist in education in general and higher education in particular, but rather what mechanisms we must implement to do this effectively and successfully. These mechanisms include the removal of obstacles, the implementation of prior guidance and advice, grants and scholarships, or the reservation of places for diverse students (Benet, 2020; Benet et al., 2019).

Proper teacher training is a critical and essential factor for the development of inclusive policies (Sharma \& Mullick, 2020). Promoting more systematic inclusion policies and support elements is possible and fundamental to foster a more truly inclusive environment for educational practice.

\subsection{Inclusive Practices of the Faculty from Universal Design for Learning}

Inclusion-based educational practices promote the participation of all students and also take into account their experiences outside the university environment (Ainscow, 2015). The role of teachers is to arrange the support needed to achieve an active learning process and motivate the participation of all students.

For this reason, university faculty members need training so they can better implement their teaching practice according to the principles of UDL, a methodology that provides different possibilities for representation, expression, and participation in relation with educational inclusion (Alba et al., 2014; Díez-Villoria \& Sánchez Fuentes, 2015; Meyer et al., 2014; Sharma \& Mullick, 2020). In fact, the goal in UDL is to improve teaching and learning for all students based on how humans learn. The Center for Applied Special Technology (CAST), an organisation for research in education development, created the framework and guidelines to implement UDL in any educational context, with the aim to improve materials, methods, and assessments (CAST, 2019; Delaney \& Hata, 2020).

The study conducted by Benet et al. (2019), with the participation of both faculty and students, highlighted the fact that classroom practice should cover three aspects: planning, development, and evaluation. In relation to planning, prior information regarding the characteristics of the student body can help to prepare teaching in a way that it better adapts to the diversity of each particular classroom. Regarding the development, the presentation of diverse materials and the use of new technologies is considered to improve accessibility for students. In addition, methodologies involving cooperative work, with heterogeneous groups, as well as those that enhance participation through the resolution of practical cases, are positively evaluated. This is also the case for practices making use of dialogical learning (Rapanta et al., 2021). Regarding the evaluation, several methods are considered, including self-assessment and peer evaluation. Feedback is essential in the students' learning process. In this way, educators obtain data with which they can guide and support their learning. To sum up, the general understanding is that inclusion-oriented practices are those where students can work together, those that promote participation and include feedback channels.

Other studies illustrate the results of implementing UDL, such as the one presented by Kennette and Wilson in 2019, where surveyed students and faculty members stated that the communication between them was one of the keys to improve learning and teaching. In fact, both students and teachers agreed on what they valued most about the methodology based on UDL: the presentation of materials in multiple ways, providing clear guidelines on assignments, answering questions outside of class time, and posting brochures and slides to their Learning Management System (Kennette \& Wilson, 2019).

In this sense, Gibson (2015) points out the need for new pedagogical developments-similar to UDL and contributing to the implementation of inclusive principlesto enhance transformative education and ensure social justice and the rights of all students.

\section{Empirical Method}

\subsection{Participants}

The target population of this study was the faculty of Spanish universities participating in the InclUni Research Project I+D. More specifically, 880 responses were obtained from faculty members of the eight participating universities, in a simple random sampling process (see Table 1).

Among the respondents, $48.50 \%$ were men and $51 \%$ were women (age average 47 years old; SD = 10.9). The average seniority within their respective institutions was 15 years of service, with a standard deviation of 11.4 . Regarding their areas, $20 \%$ worked in health, $19 \%$ in 
Table 1. Participating universities.

\begin{tabular}{lrr}
\hline Universities & $\mathrm{N}$ & $\%$ \\
\hline Universidad de Cádiz & 53 & 6.0 \\
Universidad Complutense Madrid & 391 & 44.4 \\
Universidad de Córdoba & 94 & 10.7 \\
Universidad de Jaén & 16 & 1.8 \\
Universidad Pablo de Olavide & 40 & 4.5 \\
Universidad de Sevilla & 101 & 11.5 \\
Universidad Nacional de Educación a Distancia (UNED) & 42 & 4.7 \\
Universidad de Valencia & 97 & 11.0 \\
Lost & 46 & 5.2 \\
Total & 46 & 100.0 \\
\hline
\end{tabular}

humanities, $18 \%$ in social science, $14 \%$ in experimental science, $14 \%$ in education, and $7 \%$ in engineering and technology.

Seventeen interviews were conducted to learn more about the individual experiences, attitudes, and opinions of the faculty. To select the interviewees, a purposive sampling was applied in each university, according to age, gender, macro-area of knowledge, and seniority in the institution. The sample consisted of nine women, aged 31-64, and eight men, aged 37-68. The interviews were conducted by eight project researchers from each university, based on a semi-structured script and after receiving training from the principal investigators of the project. On average, the interviews were between 45 minutes and 75 minutes long. They were audiorecorded and transcribed verbatim.

\subsection{Working Methodology}

The design of this investigation followed a mixed model. In particular, it was a non-experimental simultaneous survey design with no status distinction. Johnson and Onwuegbuzie (2004, p. 17) defined mixed designs as "the class of research where the researcher mixes or combines quantitative and qualitative research techniques, methods, approaches, concepts, or language into a single study." This kind of design was chosen following the objective of our study, to address the current state of inclusion in higher education from the perspective of the faculty, since we need to understand the thoughts and ideas of the group we are dealing with through an integrative examination of the data. We must keep in mind that we are trying to answer a complex question connected to different theoretical perspectives and a with a wide range of dialoguing and inter-connected data (Mendizábal, 2018). Only this way will we be able to better understand the phenomenon of diversity in the university.

Therefore, the study design has a quantitative stage carried out with the questionnaire, whose analysis allows us to learn about the perceptions of the faculty on diversity, and a qualitative stage (with the interviews), which provides, on the one hand, validation of the information in the questionnaire and, on the other hand, an identification of the meanings attributed to the concept of diversity. The quantitative and qualitative materials were analysed separately and integrated in the interpretation of the results. Because the interest of the study was not only to provide a quantitative 'overview' or panoramic view with which to observe the structure and stances of the faculty members regarding the concept or culture of diversity, policies and programs of the institution, and transformative practices carried out from teaching, we needed to rely on the ability of qualitative methods to delve into the content and nature of the relationships between all three dimensions analysed. This allowed us to capture details that standardisation tends to 'miss,' reinterpret some of the indicators and measurement indexes, and understand the context that fosters this specific way of understanding educational inclusion on the part of university professors. In the same line of thought, Creswell (2008) argues that mixed research goes beyond mere combination and allows the integration of quantitative and qualitative methodologies to obtain a better understanding of the object of study. In the case of mixed designs, this aspect may explain their emergence and repeated use in sciences that are directly related to social behaviours.

\subsection{Instrumentation}

Two instruments were designed: a scale and an interview.

Regarding the scale, it would be an ad hoc instrument that respondents could take themselves (through a survey in the LimeSurvey platform). The initial list was created based on the review of many previous instruments used to evaluate ideas, attitudes, and practices related to the attention to diversity. More specifically, the items were obtained following the systematic review carried out by Lombardi et al. (2018) on 69 instruments in the field of higher education and disability. In addition, the elements included in the NERCHE Self-Assessment Rubric for the Institutionalization of Diversity, Equity, and Inclusion in Higher Education (NERCHE, 2016) and Committing to Equity and Inclusive Excellence: A Campus Guide for Self-Study and Planning (American Association 
of Colleges and Universities, 2015) were also considered, resulting in a starting list of 24 items separated in eight dimensions.

In the process of creating the CAPA scale (for the Spanish initials of Beliefs, Attitudes, and Practices of Attention to Diversity), the method chosen for reviewing the validity of the content was the calculation of descriptors by determining the content validity index (Ramos et al., 2021). This index is obtained from the evaluation of 15 experts regarding the representativeness, relevance, and adequacy of each item, as well as their comprehensibility, ambiguity, and clarity. After confirming the agreement, the CAPA scale was formed and a pilot application was shared with the faculty of the Spanish universities collaborating in the InclUni project, in a starting sample of 214 educators (Ramos et al., 2019). The reliability analysis-internal consistencyoffered a Crombach's alpha value of 0.89 and the factorial research-exploratory and confirmatory-carried out shows a well-adjusted model composed of 19 items and structured in five factors: (1) institutional diversity, (2) research, training, and teaching with attention to diversity, (3) teaching-learning practices, (4) commitment of the governing bodies, and (5) concept of diversity.

Regarding the interview, the following documents were used to determine the questions in the script: Committing to Equity and Inclusive Excellence: A Campus Guide for Self-Study and Planning (American Association of Colleges and Universities, 2015), the Declaration on Promoting Citizenship and the Common Values of Freedom, Tolerance and Non-Discrimination through Education (European Union, 2015), and the NERCHE Self-Assessment Rubric for the Institutionalization of Diversity, Equity, and Inclusion in Higher Education (NERCHE, 2016).

Thus, a first section was created with identification data and a second group collected information about the respondent's concept of diversity, programmes, policies, and actions, and commitment and proposals (see the interview items in the Supplementary File).

\subsection{Statistical Analysis}

Different statistical tests were made using version 24 of the Statistical Package for the Social Sciences (SPSS) to analyse the questionnaire responses. For the 17 interviews, the Maxqda 2018.2 software was used. Coding and analysis was performed by a single researcher using Maxqda software, following different phases: (1) open and inductive coding, (2) categorisation-consisting of grouping and reorganising codes to provide an interpretive and inferential analysis related to the concept of 'attention to diversity' in higher education, inclusive policies at university, and faculty inclusive practices such as collaborative learning, project-based learning, continuous assessment (all of them included in the UDL)-and (3) writing the final report after a critical review and the creation of semantic networks (Braun \& Clarke, 2006).

\subsection{Results}

First, we show the results of the 880 questionnaires; following that, the reader will find the results extracted from the interviews. In both cases, information was analysed based on diversity concept or culture, policies and programmes of the institution, and inclusive practices.

\subsubsection{Quantitative Results}

The global average of the 19 items in the scale is 3.65 (five-point scale), with a standard deviation of 0.64 , which implies an overall satisfactory assessment of attention to diversity by the faculty. The five factors in the questionnaire have been synthesised in the topics covered in our article: diversity concept or culture (with five items), inclusive policies and programmes ( 6 items), and inclusive practices ( 8 items; see Table 2 ). The issue with the most agreement (average $=3.97$ ) among faculty members was the concept of diversity. In general, they have similar diversity concepts or cultures. Regarding the policies and programmes proposed by the institution (average $=3.71$ ), the perceptions also concentrate around the idea that the institutions are considering and promoting these aspects. Lastly, the topic educators seem to be less satisfied with their own inclusive practices (average $\mathbf{~} 3.41$ ).

Regarding the concept of diversity, the different answers show that faculty members completely agree that diversity, inclusion, and equity are essential in education and must be addressed in every educational centre (item 4), both institutionally and individually (item 5), but there is less agreement on diversity referring to students with different educational level (item 3).

Concerning inclusive practices-and according to each item-the perception of the faculty is very positive regarding the need to train students to succeed in a diverse world (item 7) and, at the same time, develop specific actions to meet the diversity of the student body. There is less agreement on whether there is an ingrained culture of diversity, inclusion, and equity in curricular choices (item 10) and whether the institutions should offer specific material focusing on the role of women and minorities in university curricula (item 6). Gender differences and the attention to certain minorities continue to be overlooked and are not considered as part of the diversity that needs to be addressed. Only from a broader perspective is it possible to take them into account (Moriña, 2017).

Looking at inclusive educational practices, the most widespread agreement relates to the faculty's support to help students develop individualised plans so that they can learn better (item 16). Conversely, very few educators design innovative teaching projects with an attention to gender, age, culture, and religious diversity, among others (item 14).

Having mostly high scores in the responses shows a very positive trend among university faculty. It makes us 
Table 2. Average, standard deviation, skewness, and kurtosis of the beliefs, attitudes, and practices related to the attention to diversity.

\begin{tabular}{|c|c|c|c|c|}
\hline \multicolumn{2}{|c|}{ Diversity concept or culture } & \multirow{2}{*}{$\frac{\text { Average }(\sigma)}{3.99(1.15)}$} & \multirow{2}{*}{$\begin{array}{c}\text { Sk. } \\
-1.21\end{array}$} & \multirow{2}{*}{$\begin{aligned} \text { Kur. } \\
.73\end{aligned}$} \\
\hline 1 & The concept of diversity means different ethnicity, race, nationality, or culture & & & \\
\hline 2 & ... means people with different thoughts and ideas & $3.92(1.24)$ & -1.12 & .27 \\
\hline 3 & ... means different level of education & $3.12(1.44)$ & -.19 & -1.29 \\
\hline 4 & $\begin{array}{l}\text { Diversity, inclusion, and equity are essential in education and must be } \\
\text { addressed in any university institution }\end{array}$ & $4.42(.93)$ & -1.79 & 2.88 \\
\hline 5 & $\begin{array}{l}\ldots \text { are an institutional matter, but also an individual one, for each member of } \\
\text { the institution }\end{array}$ & $4.44(.88)$ & -1.99 & 4.44 \\
\hline \multicolumn{2}{|c|}{ Dimension average } & $3.97(.79)$ & -.87 & 1.17 \\
\hline \multicolumn{2}{|c|}{ Inclusive policies and programmes } & Average $(\sigma)$ & Sk. & Kur. \\
\hline 6 & $\begin{array}{l}\text { Specific subjects focusing on the role of women and minorities should be } \\
\text { integrated into university curricula }\end{array}$ & $3.43(1.35)$ & -.38 & -1.03 \\
\hline 7 & $\begin{array}{l}\text { For universities, training people to succeed in a diverse world is as } \\
\text { important as providing them with technical or academic skills }\end{array}$ & $4.08(1.04)$ & -1.16 & .85 \\
\hline 8 & $\begin{array}{l}\text { Universities should develop specific actions to address diversity in the } \\
\text { student body }\end{array}$ & $4.10(1.07)$ & -1.25 & 1.06 \\
\hline 9 & $\begin{array}{l}\text { In general, the management team of my university or centre promotes } \\
\text { diversity, inclusion, and equity actions }\end{array}$ & $3.64(.95)$ & -.47 & .20 \\
\hline 10 & $\begin{array}{l}\text { My university or centre has a deep-rooted tradition in favour of diversity, } \\
\text { inclusion, and equity in curricular choices }\end{array}$ & $3.34(.98)$ & -.23 & -.16 \\
\hline 11 & $\begin{array}{l}\text { My university offers training courses related to diversity, inclusion, } \\
\text { and equity }\end{array}$ & $3.68(.98)$ & -.48 & -.09 \\
\hline \multicolumn{2}{|c|}{ Dimension average } & $3.71(.68)$ & -.67 & .83 \\
\hline \multicolumn{2}{|c|}{ Inclusive practices } & Average $(\sigma)$ & Sk. & Kur. \\
\hline 12 & $\begin{array}{l}\text { I develop research that reflects, in form and/or content, my commitment } \\
\text { to diversity, inclusion, and equity as an added value to the research project }\end{array}$ & $3.23(1.35)$ & -.27 & -1.04 \\
\hline 13 & $\begin{array}{l}\text { I incorporate into my research designs elements that favour the diversity, } \\
\text { inclusion, and equity of cultures, gender, and age, among others }\end{array}$ & $3.23(1.34)$ & -.33 & -.99 \\
\hline 14 & $\begin{array}{l}\text { I design innovative teaching projects with an attention to gender, age, } \\
\text { culture, and religious diversity, among others }\end{array}$ & $2.62(1.37)$ & .25 & -1.15 \\
\hline 15 & I design and monitor the results of teaching goals focused on equity & $3.35(1.30)$ & -.42 & -.84 \\
\hline 16 & I provide support to help my students develop individualised learning plans & $3.85(1.06)$ & -.84 & .27 \\
\hline 17 & $\begin{array}{l}\text { In my classes, I implement different teaching-learning methodologies to } \\
\text { cater for the diversity of the students }\end{array}$ & $3.64(1.13)$ & -.64 & -.20 \\
\hline 18 & $\begin{array}{l}\text { I offer resources to respond to the needs of students and to address the } \\
\text { development of inclusive education }\end{array}$ & $3.68(1.12)$ & -.79 & -.09 \\
\hline 19 & $\begin{array}{l}\text { In my subjects I include digital learning and/or cooperative activities to } \\
\text { promote learning for students with different needs }\end{array}$ & 3.66 (1.17) & -.70 & -.25 \\
\hline \multicolumn{2}{|c|}{ Dimension average } & $3.41(.92)$ & -.34 & -.29 \\
\hline
\end{tabular}

think that they have a clear predisposition to get involved in a process of attention to diversity.

We must note that most items-with the exception of item 14-have a negative bias and a kurtosis with mostly negative values-11 of the total $19-$ with all but item 5 showing values under 3.0, which marks normality criteria, according to Chou and Bentler (1995) (see Table 2).

Regarding the correlation analysis, we must point out that the connection between different items in the questionnaire, according to De Vaus (2001), is between moderate (0.303) and high (0.846), in most cases with a significance level of $p<0.01$. Even correlations under the moderate score show significance levels of $p<0.01$. The highest correlations are found in items related to inclusive practices (items 12, 13, 14, 15, 17, 18, and 19) and items related to policies and programmes (items $5,6,7$, and 8 ), as well as between the items of those two factors. This is indicative that there is a strong link between the implementation of inclusive policies in 
higher education institutions and teaching practices that address the diversity of the university students.

\subsubsection{Qualitative Results}

The analysis and interpretation of qualitative data was carried out in an inductive thematic analysis (Braun \& Clarke, 2006), that made it possible to choose the categories according to the main topics to be addressed in this document. A total of 1574 segments were coded, separated into 19 categories. The closest ones to our topics, which were also the most common, were analysed.

Results are presented combining academic commentary with diagrams and verbatim quotations from the participants. Each piece of evidence points to the document it can be found in and the paragraph number where it can be located, according to the quality criteria manifested in Consolidated Criteria for Reporting Qualitative Research (Tong et al., 2007).

Regarding the participants' diversity concept and culture, 239 segments were coded in the 17 interviews: $25.94 \%$ of them related to diversity in their work, $19.67 \%$ to evidence of diversity, and $16.74 \%$ about whether they feel prepared to work with diversity.

The perceptions of university faculty members regarding inclusion are quite homogeneous among the eight analysed universities. Most participants identify themselves with a definition of diversity understood as difference.

The balance found between two opposing perceptions is certainly striking: There are faculty members who are not prepared to address diversity in their university classroom (57.9\%) and require specific training beyond the adaptations provided by existing university units, and then there are those who do feel capable to do it (42.1\%). The following are some of the faculty's ideas extracted from the interviews:

No, we are not prepared....There is a need for better faculty awareness, and... aids for the development of teaching materials. (4 UCM W, 71)

We try, we do the best we can, but I don't... I don't... I am not sure that I am perfectly prepared, but we do what we can. (1 UCA M, 37)

In this section on inclusive policies and programmes, the vision of institutional diversity and the degree of coherence with the university's understanding of it are examined (there are a total of 410 segments on the subject). Regarding the principles that govern the university's approach to diversity, the principles of normalisation and inclusion were mentioned. As to whether inclusion is a priority principle, there are those who perceive it is, in contrast to critical views to the contrary.

The teaching staff's perception of the evolution of these policies has shown a quantitative and qualitative evolution; there is clear progress and sensitivity.
On university social responsibility as a specific university policy linked to diversity and inclusion, all the faculty members interviewed express their views on it. They explicitly define it as a social responsibility, even as a right and an obligation to interact with society and return the investment made on it:

I think so, my understanding is that the policy of attention to diversity that is developed within universities is part of that commitment, of that social responsibility that the university should have towards society (forgive the repetition). (7 UJA M, 18)

As for university policies related to attention to diversity, there is evidence that it is considered to be fundamental and a priority. However, it is worth noting that many teachers say that they are unaware of the policies of their institution regarding the attention to diversity.

Concerning the topic of inclusive teaching practices, the participants paid particular attention to the motivation to carry out inclusive programmes and actions, and they have questions regarding methodological processes, resources, etc., as well as the actions to respond to diversity. More specifically, 254 segments were found related to this issue.

Some faculty members do not address diversity in any subject, although they do adapt them when necessary. Some consider that diversity is already present in some specific degrees or even in a transversal way. Others state that they integrate diversity in their subject, and one of the respondents mentioned the challenge to meet the needs of a student with Asperger's syndrome without the rest of the students noticing that he was receiving special attention.

Concerning the methodologies they use, there is, again, evidence of a variety of stances: some state that they do not use any particular methodology to work on diversity, and other do. Among the latter, some aspects that professors mention are:

- The usefulness of working in heterogeneous groups.

- The implementation of inclusion in the methodology of work projects, in cooperative work, etc.

- The possibility that the students themselves create activities for a subject.

- Methodologies based on Freinet or Freire.

- Service-learning methodology.

All of these methodologies are part of the UDL as different ways of applying actions aimed at learning for all, based on the inclusive perspective of Dyson (1999).

Finally, Figure 1 shows the main difficulties that the interviewed faculty members identify. They focus on the lack of training and strategies to address diversity, as well as the lack of awareness action (associated with excessive workload). 
Difficulties

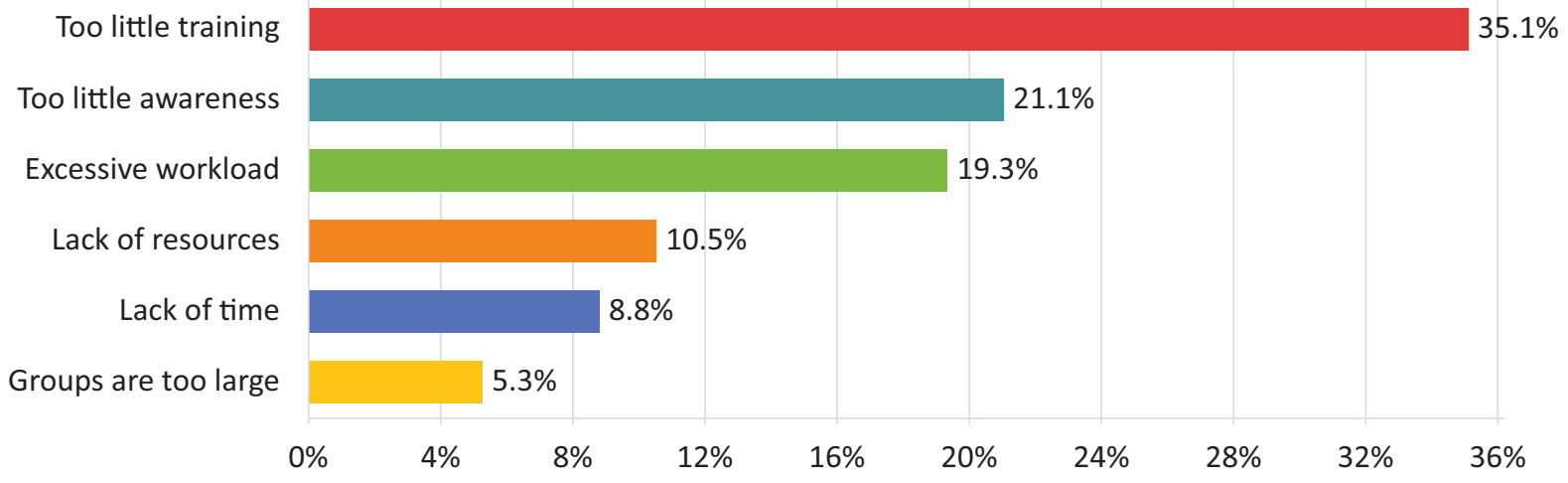

Figure 1. Main difficulties identified by the interviewed faculty members regarding the attention to diversity.

\section{Discussion}

As we indicated at the beginning of the article, our goal is to address the current state of inclusion in higher education from the perspective of the teaching staff with respect to three areas: diversity concept or culture, policies and programmes of the institution, and transformative practices carried out from teaching. The results allow us to reach the following conclusions:

University faculty members have a positive predisposition to become involved in the process of attention to diversity at the conceptual, practical, and policy levels. As indicated by Ainscow et al. (2013) and Díaz-Jiménez (2019), teachers believe that the university should participate in the overall process of inclusion, as evidenced by their perception of it.

Regarding the concept of diversity, most of the teaching staff who participated in the study understand it from the perspective of inclusion and equity. They think it is an essential part of education, both an institutional and an individual responsibility, and they identify to a greater extent with a definition based on functional and cognitive differences (Benet et al., 2019; Biewer et al., 2015; Díaz-Jiménez, 2019; Grant \& Allweiss, 2014).

In terms of inclusive policies, at a quantitative level, there is a very positive perception of the support for the development of specific actions to address the diversity of the student body. Educators want universities to include curricular subjects that respond to the needs of protected groups (Benet et al., 2019; Moriña, 2017).

Regarding inclusive teaching practices, the teaching staff note that research and innovation are developed to a lesser extent from the commitment to diversity, highlighting that such commitment is greater at the individual level, as reflected in the teaching methodology and resources used. The educators under study do not feel well prepared to deal with diversity, nor do they feel sufficiently aware of everything it entails. Therefore, as Sharma and Mullick (2020) indicate, a fundamental pillar to be considered in the development of inclusive policies is the adequate training of university teaching staff.

\section{Conclusion}

The value of working with heterogeneous groups to enrich the classroom and, in general, the need to use cooperative methodologies that promote values such as solidarity and group cohesion is evident in the responses (Booth \& Ainscow, 2015; Rapanta et al., 2021). All these methodologies used by faculty in the classroom are part of the UDL (Benet et al., 2019; Kennette \& Wilson, 2019; Rapanta et al., 2021).

Therefore, the faculty's proposals for inclusive action in the university context revolve around the following ideas: on the one hand, overcoming the concept of diversity associated only with functional and cognitive aspects (Hardy \& Woodcock, 2015), systematising policies that promote research, innovation, and teaching to continue promoting the commitment and social responsibility of higher education institutions and thus enhance the process of educational inclusion (Ainscow, 2015; Ainscow et al., 2013; Díaz-Jiménez, 2019). On the other, analysing and reflecting on the need for better teacher training, as teachers express an interest in learning more about methodologies for raising awareness and dealing with diversity (Sharma \& Mullick, 2020). Several authors (Alba et al., 2014; Benet et al., 2019; Delaney \& Hata, 2020; Kennette \& Wilson, 2019; Meyer et al., 2014; Rapanta et al., 2021) indicate that UDL is one of the key methodologies that can help educators in their attention to student diversity, so it would be necessary to establish training plans in this regard. University faculty's UDL training is proposed as a universal learning approach for all students (Dyson, 1999). It will contribute to the development of inclusive principles through enhancing strategies to improve the learning process and, therefore, to promote social inclusion.

Clearly, governments must commit firmly through university policies to invest in teacher training in inclusive practices and contribute to create the resources necessary to make it possible. 


\section{Acknowledgments}

The study reported in this article was supported by the Spain Ministry of Economy, Industry, and Competitiveness, the State Research Agency, and the European Regional Development Fund (grant number EDU2017-82862-R)

\section{Conflict of Interests}

The authors declare no conflict of interests.

\section{Supplementary Material}

Supplementary material for this article is available online in the format provided by the author (unedited).

\section{References}

Ainscow, M. (2015). Towards self-improving school systems: Lessons from a city challenge. Routledge.

Ainscow, M., Dyson, A., Goldrick, S., \& West, M. (2013). Promoviendo la equidad en educación [Promoting equity in education]. Revista de Investigación en Educación, 11(3), 44-56.

Alba, C., Sánchez, J. M., \& Zubillaga, A. (2014). Diseño universal para el aprendizaje. Pautas para su introducción en el currículo [Universal design for learning: Guidelines for its introduction in the curriculum]. Ministerio de Economía y Competitividad. http:// www.educadua.es/doc/dua/dua_pautas_intro_ cv.pdf

American Association of Colleges and Universities. (2015). Committing to equity and inclusive excellence: A campus guide for self-study and planning. American Association of Colleges and Universities. http:// www.aacu.org/sites/default/files/Committingto EquitylnclusiveExcellence.pdf

Benet, A. (2020). Development of inclusive policies in higher education. Convergencia. Revista de Ciencias Sociales, 27, 1-31. https://doi.org/10.29101/ crcs.v27i82.11120

Benet, A., Sales, A., \& Moliner, O. (2019). Construyendo universidades inclusivas: Elementos clave de las prácticas docentes [Building inclusive universities: Key elements of teaching practices]. Revista de Educación Inclusiva, 12(2), 78-100.

Biewer, G., Buchner, T., Shevlin, M., Smyth, F., Šiška, J., Kánová, Š., Ferreira, M., Toboso-Martín, M., \& Rodríguez-Díaz, S. (2015). Pathways to inclusion in European higher education systems. Alter, 9(4), 278-289. https://doi.org/10.1016/j.alter.2015. 02.001

Booth, T., \& Ainscow, M. (1998). From them to us. Routledge.

Booth, T., \& Ainscow, M. (2015). Guía para la educación inclusiva: Desarrollando el aprendizaje y la participación en los centros escolares (3rd ed.) [Guidelines for inclusive education: Developing learning and participation in schools]. FUHEM, OEI.

Braun, V., \& Clarke, V. (2006). Using thematic analysis in psychology. Qualitative Research in Psychology, 3(2), 77-101. https://doi.org/10.1191/1478088706 qp063oa

Center for Applied Special Technology. (2019). About universal design of learning. CAST. http://www.cast.org/ our-work/about-udl.html\#.XyHq1vhKjfZ

Chou, C. P., \& Bentler, P. M. (1995). Estimates and tests in structural equation modeling. In R. H. Hoyle (Ed.), Structural equation modeling: Concepts, issues, and applications (pp. 37-55). Sage.

Creswell, J. W. (2008). Educational research: Planning, conducting, and evaluating quantitative and qualitative research (3rd ed.). Pearson Education.

De Vaus, D. (2001). Research design in social research. Sage.

Delaney, T. A., \& Hata, M. (2020). Universal design for learning in assessment: Supporting ELLs with learning disabilities. Latin American Journal of Content \& Language Integrated Learning, 13(1), 79-91. https:// doi.org/10.5294/laclil.2020.13.1.5

Díaz-Jiménez, R. M. (Ed.). (2019). Universidad inclusiva. Experiencias con personas con diversidad funcional cognitiva [Inclusive university. Experiences with people with cognitive functional diversity]. Pirámide.

Díez-Villoria, E., \& Sánchez Fuentes, S. (2015). Universal design for learning as a teaching method in order to meet the need for diversity in universities. Aula Abierta, 43(2) 87-93. https://doi.org/10.1016/j.aula. 2014.12.002

Dyson, A. (1999). Inclusion and inclusions: Theories and discourses in inclusive education. In $\mathrm{H}$. Daniels \& P. Garner (Eds.), World yearbook of education 1999: Inclusive education (pp. 45-53). Routledge.

European Agency for Special Needs and Inclusive Education. (2012). Teacher education for inclusion profile of inclusive teachers. European Agency. https://www.european-agency.org/sites/default/ files/Profile-of-Inclusive-Teachers.pdf

European Commission. (2010). European disability strategy 2010-2020: A renewed commitment to a barrierfree Europe (COM (2010) 636 final). European Commission. https://eur-lex.europa.eu/LexUriServ/ LexUriServ.do?uri=COM:2010:0636:FIN:en:PDF

European Commission. (2018). Council recommendation on promoting common values, inclusive education, and the European dimension of teaching (COM (2018) 23 final). European Commission. https://ec. europa.eu/transparency/regdoc/rep/1/2018/EN/ COM-2018-23-F1-EN-MAIN-PART-1.PDF

European Union. (2015). Declaration on promoting citizenship and the common values of freedom, tolerance and non-discrimination through education. European Union. http://ec.europa.eu/dgs/ education_culture/repository/education/news/2015/ documents/citizenship_education-declaration_en.pdf 
Eurydice. (2011). La modernización de la educación superior en Europa [Modernisation of higher education in Europe]. EACEA.

Forlin, C., Earle, C., Loreman, T., \& Sharma, U. (2011). The sentiments, attitudes, and concerns about inclusive education revised (SACIE-R) scale for measuring preservice teachers' perceptions about inclusion. Exceptionality Education International, 21(3), 50-65.

Gibson, S. (2015). When rights are not enough: What is? Moving towards new pedagogy for inclusive education within UK universities. International Journal of Inclusive Education, 19(8), 875-886.

Goldberg, A. E., Beemyn, G., \& Smith, J. Z. (2019). What is needed, what is valued: Trans students' perspectives on trans-inclusive policies and practices in higher education. Journal of Educational and Psychological Consultation, 29(1), 27-67. https://doi.org/10.1080/ 10474412.2018.1480376

Grant, C., \& Allweiss, A. (2014). Tracing the arc: The shifting conceptualizations of educational "disadvantage" and "diversity" at the university of WisconsinMadison. Social Inclusion, 2(1), 34-46.

Hardy, I., \& Woodcock, S. (2015). Inclusive education policies: Discourses of difference, diversity and deficit. International Journal of Inclusive Education, 19(2), 141-164. https://doi.org/10.1080/13603116. 2014.908965

Johnson, R. B., \& Onwuegbuzie, A. J. (2004). Mixed methods research: A research paradigm whose time has come. Educational Researcher, 33, 14-26. http://dx. doi.org/10.3102/0013189X033007014

Kennette, L. N., \& Wilson, N. A. (2019). Universal design for learning (UDL): Student and faculty perceptions. Journal of Effective Teaching in Higher Education, 1(2). https://eric.ed.gov/?id=EJ1214930

Kestin, T., van den Belt, M., Denby, L., Ross, K. E., Thwaites, J., \& Hawkes, M. (2017). Getting started with SDG in universities: A guide for universities, higher education institutions, and the academic sector. Sustainable Development Solutions Network Australia/Pacific. http://hdl.handle.net/10453/ 124261

Klein, U. (2016). Gender equality and diversity politics in higher education: Conflicts, challenges and requirements for collaboration. Women's Studies International Forum, 54, 147-156. http://dx.doi.org/ 10.1016/j.wsif.2015.06.017

Langa-Rosado, D., \& Lubián-Graña, C. (2021). La Atención a la Diversidad en las universidades españolas a través de los discursos de sus líderes [Attention to diversity in spanish universities through the speeches of their leaders]. Revista Complutense de Educación, 32(1), 79-88. https://doi.org/10.5209/rced.68022

Lombardi, A., Gelbar, N., Dukes, L. L., Kowitt, J., Wei, Y., Madaus, J., Lalor, A. R., \& Faggella-Luby, M. (2018). Higher education and disability: A systematic review of assessment instruments designed for students, faculty, and staff. Journal of Diversity in Higher Education, 11(1), 34-50. https://doi.org/ 10.1037/dhe0000027

Lombardi, A., Vukovic, B., \& Sala-Bars, I. (2015). International comparisons of inclusive instruction among college faculty in Spain, Canada, and the United States. Journal of Postsecondary Education and Disability, 28(4), 447-460.

Mendizábal, N. (2018). La osadía en la investigación: El uso de los Métodos Mixtos en las ciencias sociales. [Boldness in research: The use of mixed methods in social sciences]. Espacio Abierto, 27(2), 5-20.

Meyer, A., Rose, D. H., \& Gordon, D. (2014). Universal design for learning: Theory and practice. CAST Professional Publishing.

Moliner, L., \& Moliner, M. O. (2010). Percepciones del profesorado sobre la diversidad. Estudio de un caso. [Teacher perceptions of diversity. A case study]. Revista de Educación Inclusiva, 3(3), 23-34. http:// www.ujaen.es/revista/rei/linked/documentos/ documentos/11-2.pdf

Moriña, A. (2017). Inclusive education in higher education: Challenges and opportunities. European Journal of Special Needs Education, 32(1), 3-17. https:// doi.org/10.1080/08856257.2016.1254964

Moriña, A., López-Gavira, R., \& Molina, V. M. (2017). What if we could imagine an ideal university? Narratives by students with disabilities. International Journal of Disability, Development and Education, 64(4), 353-367. https://doi.org/10.1080/1034912X. 2016.1228856

NERCHE. (2016). NERCHE self-assessment rubric for the institutionalization of diversity, equity, and inclusion in higher education. New England Resource Center for Higher Education. http://nerche.org/index. php?option=com_content $\&$ view $=$ article $\& i d=971 \&$ Itemid $=157$

O'Donnell, V. L. (2016). Organisational change and development towards inclusive higher education. Journal of Applied Research in Higher Education, 8(1), 101-118. https://doi.org/10.1108/JARHE-042014-0051

Ramos, G., Chiva, I., Pérez-Carbonell, A., \& Moral, A. (2019, June 19-21). Validación de la Escala Creencias, Actitudes y Prácticas de Atención a la Diversidad del Profesorado Universitario [Validation of the beliefs, attitudes and practices of university faculty in attention to diversity scale [Paper Presentation]. $X I X$ Congreso Internacional de Investigación Educativa: Investigación Comprometida para la Transformación Social, Madrid.

Ramos, G., Pérez-Carbonell, A., Chiva, I., \& Moral, A. (2021). Validation of a scale of attention to diversity for university teachers. Educación XX1, 24(2), 121-142. https://doi.org/10.5944/educXX1.28518

Rapanta, C., Garcia-Mila, M., Remesal, A., \& Gonçalves, C. (2021). The challenge of inclusive dialogic teaching in public secondary school. Comunicar, 66, 9-20. https://doi.org/10.3916/C66-2021-02 
Sharma, U., \& Mullick, J. (2020). Bridging the gaps between theory and practice of inclusive teacher education. Oxford Research Encyclopedias. https://doi.org/10.1093/acrefore/9780190264093. 013.1226

Tong, A., Sainsbury, P., \& Craig, J. (2007). Consolidated criteria for reporting qualitative research (COREQ):
A 32-Item checklist for interviews and focus groups. International Journal for Quality in Health Care, 19, 349-357. https://doi.org/10.1093/intqhc/mzm042

United Nations. (2015). Transforming our world: The 2030 agenda for sustainable development (A/RES/70/1). United Nations. https://sdgs.un.org/ 2030agenda

\section{About the Authors}

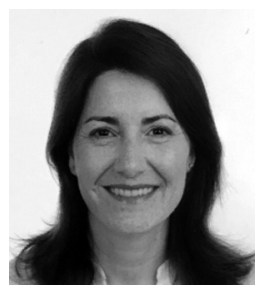

Ana Maria Moral Mora works as an Assistant Professor at the Department of Research Methods and Educational Diagnosis in the Faculty of Philosophy and Education Sciences, University of Valencia, since 2003. She holds a PhD in Pedagogy and is a member of the research team DIVFOREVA-UV of the University of Valencia. Her research focuses on educational assessment, school coexistence, and attention to diversity in social and educational contexts. https://orcid.org/0000-0002-6073-3121

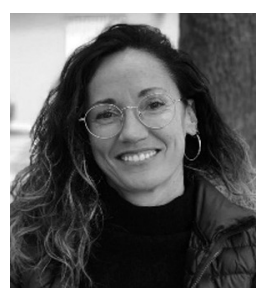

Inmaculada Chiva holds a PhD in Philosophy and Science of Education from the University of Valencia, where she is now Full Professor of Research Methods and Educational Diagnosis. Her main research lines include the evaluation of programs, studies on the quality of primary and secondary education, teacher training, design of instruments, e-evaluation of university students, and attention to diversity, among others. She is part of the research group DIVFOREVA-UV. https://orcid.org/0000-0002-71452309

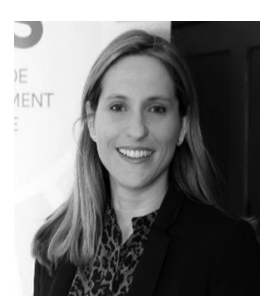

Carmen Lloret-Catala is a Professor at the Department of Comparative Education and Education History in the Faculty of Philosophy and Educational Sciences, University of Valencia, since 2010. Her research interests focus on the topics of cooperation for educational development, social responsibility (RS), inclusive policies, and educational technology. Since 2018 she also works as the delegate of the principal of the University of Valencia for cooperation for development. https://orcid.org/00000003-3366-0390 